\title{
Reduced Herbicide Leaching by in Situ Adsorption of Herbicide- Micelle Formulations to Soils
}

\author{
Haim $\mathrm{Katz}^{\dagger}$ and Yael G. Mishael* \\ Department of Soil and Water Sciences, The Robert H. Smith Faculty of Agriculture, Food and Environment, Hebrew University of \\ Jerusalem, Rehovot 76100, Israel
}

ABSTRACT: Aiming to reduce herbicide leaching, "in situ" adsorption of herbicide-micelle formulations to soils was explored. Sulfentrazone or metolachlor were solubilized in cationic micelles, and these herbicide-micelle formulations were applied to sandy and alluvial soils. Sulfentrazone adsorption to the soils was negligible; however, its adsorption via its solubilization in micelles and their adsorption to the soil was significant and in good agreement with the Freundlich and Langmuir models. Adsorption of solubilized herbicide to the sandy soil was higher than to the alluvial soil. The low ratio between the surfactant concentration and the cation exchange capacity (CEC) of the alluvial soil brought upon micelle decomposition and reduction in herbicide adsorption. Therefore, an optimized ratio between surfactant and soil CEC was chosen to maximize herbicide retention. Even upon adding relatively low loadings of surfactant $(0.075-0.3 \% \mathrm{w} / \mathrm{w}$ soil), herbicide leaching through the soils was significantly reduced (2-5-fold) in comparison with the commercial formulations.

KEYWORDS: reduced leaching, slow release formulations, surfactants, sulfentrazone, metolachlor

\section{INTRODUCTION}

Herbicides provide substantial agronomic and economic benefits. However, introducing bioactive molecules to the environment poses environmental issues including their leaching and surface migration, which may cause soil, surface, and groundwater contamination. ${ }^{1,2}$ Furthermore, migration and leaching reduce herbicide concentration at the topsoil which reduces weed control efficacy. Herbicide leaching in the soil is governed by several factors, such as soil characteristics, chemophysical properties of herbicides, the effect of climatic conditions, and tillage methods. 1,3

In the current study the extensive leaching of sulfentrazone and metolachlor, which have been detected in groundwater, ${ }^{4-6}$ is addressed. Sulfentrazone (water solubility of $\sim 280 \mathrm{ppm}$ ) is an anionic herbicide $\left(\mathrm{p} K_{\mathrm{a}}=6.56\right)$, its mobility enhances with the increase in soil $\mathrm{pH}$, and its adsorption to the soil especially at alkaline pHs is negligible. ${ }^{7}$ Metolachlor, although nonionic, is relatively soluble in water $(490 \mathrm{ppm}),{ }^{8}$ and its sorption to soils is considered not high.'

The main approaches to reduce herbicide leaching are herbicide dose optimization, site specific weed management, and nonchemical weed control such as mechanical and thermal. Another approach widely pursued in the past few decades is developing slow release formulations, ${ }^{10-33}$ many of which are based on organically modified clay minerals ${ }^{10,12,15-17,19,24,26-35}$ including organoclays, ${ }^{11,15,16,19,31,32,34,36}$ polymerclays, $^{23,24,29,30,33}$ and micelle-clays. ${ }^{20,25,28,35}$ Several of these formulations were tested and found to reduce leaching through soil columns; however, their preparation is inefficient since it entails large water volumes, loss of active ingredient, drying, grinding the formulation and resuspending the powdered formulations, etc.

Therefore, an alternative approach of in situ formation of organo-clay sorbents for herbicide retention, by adding the organic cations to the soil, was developed. ${ }^{37-39}$ A few studies have reported the enhanced adsorption of herbicides (and other organic contaminants) in soils treated with surfactants. ${ }^{40-42}$ However, these reports did not include leaching studies nor did they address herbicide solubilization in micelles, since surfactant concentrations were below the critical micelle concentration (CMC).

The phenomenon of solubilization, increasing the solubility of an insoluble or poorly soluble organic substance in a surfactant solution, has been widely studied for many decades and is well-established in different fields such as medicine, cosmetics, detergency, and environment. ${ }^{43-48}$ For example, studies on soil remediation by "enhanced pump and treat" have addressed the issue of surfactant concentration below and above their CMC and indicated that upon formation of micelles in the solution pollutant mobility was enhanced. ${ }^{49,50}$

In previous studies on micelle-clay slow release formulations, $^{25,26,35}$ we demonstrated that herbicides (sulfumeturon and sulfosulfuron) adsorption to the clay is enhanced when the surfactant is adsorbed as micelles (vs monomers). In a later study we described the mechanism of sulfentrazone and metolachlor solubilization in octadecyltrimethylammonium (ODTMA) micelles and characterized the herbicide-micelle adsorption to the clay. The percent of active ingredient (sulfentrazone and metolachlor) in clay formulations based on solubilization of the active ingredient in micelles is 4-fold higher than in organo-clay formulations. ${ }^{11}$

These clay based formulations have been tested and found to reduce leaching through soil columns; however, their application in the field is problematic due to inefficient preparation as described above.

Received: August 20, 2013

Revised: November 25, 2013

Accepted: December 2, 2013

Published: December 2, 2013 
In the current study, we suggest designing herbicidemicelle-clay formulations in which the clay is not an external ingredient but rather part of the target soil. The herbicide is solubilized in micelles, the herbicide-micelle formulation is directly applied to the soil, and herbicide leaching through the soil is suppressed due to its sorption, via micelle adsorption, to the soil. The herbicide and micelles are applied to the soil at the same time, in comparison to the two step application in other reports (soil modification and then herbicide application) which is advantageous. Furthermore, an "in situ" mode increases the percent of active ingredient, and since there is no clay in the employed formulation, preparation and application in the field is simplified.

\section{MATERIALS AND METHODS}

Materials. Wyoming Na-montmorillonite (SWy-2) (cation exchange capacity, $0.76 \mathrm{mmol} / \mathrm{g}$; surface area, $700 \mathrm{~m}^{2} / \mathrm{g}$ ) was obtained from the Source Clays Repository of the Clay Mineral Society (Columbia, MO). Octadecyltrimethylammonium bromide (ODTMA) and Triton X-100 were purchased from Sigma-Aldrich (Stenheim, Germany). Acetonitrile and water, high-performance liquid chromatography (HPLC) grade, were purchased from Merck (Darmsradt, Germany). Sulfentrazone N-[2,4-dichloro-5-[4-(difluoromethyl)-4,5dihydro-3-methyl-5-oxo-1 $H$-1,2,4-triazol-1-yl[phenyl]methane-sulfonamide technical (purity 91.3\%) was received from FMC (Princeton, $\mathrm{NJ})$. Boral is a commercial formulation of the ai sulfentrazon $(75 \%$ ai, water dispersible granular) $480 \mathrm{~g}$ ai/L liquid), metolachlor 2-chloro- $\mathrm{N}$ (6-ethyl-o-tolyl)- $N$-[(1RS)-2-methoxy-1-methylethyl] acetamide technical (purity 98.6\%), and commercial metolachlor (Dual-Gold $915 \mathrm{~g}$ ai/L liquid), which were obtained from Agan Chemicals (Ashdod, Israel). Rehovot sandy soil ${ }^{51}$ was collected from the faculty's experimental farm. An Alluvial soil was collected from fields located a few miles east of the faculty's experimental farm (Na'an). The soil samples were air-dried and sieved through a $2 \mathrm{~mm}$ screen. The soils characteristics are shown in Table 1.

\section{Table 1. Soil Characterization}

\begin{tabular}{lcrcccc}
\multicolumn{1}{c}{ soil } & sand \% & silt \% & clay \% & $\mathrm{pH}$ & OM \% & CEC [mequiv/100 g] \\
alluvial & 43.3 & 14.9 & 41.8 & 7.6 & 1.05 & 48.5 \\
sandy & 95.5 & 3.3 & 1.2 & 7.5 & 0.2 & 6.0 \\
\hline
\end{tabular}

Methods. Preparation of Herbicide-Micelle Formulations and Micelle-Clay and Herbicide-Micelle-Clay composites for Zeta Potential Measurements. Throughout the study, the preparation of ODTMA micelles included heating the solutions to exceed the Krafft temperature, $T_{\mathrm{K}}$ point $\left(40{ }^{\circ} \mathrm{C}\right)$ and reach a clear solution. Sulfentrazone (0.75-4.2 mmol/L) was added to an ODTMA solution $(2.8 \mathrm{mM})$ which was stirred for $24 \mathrm{~h}$. Micelle-clay and herbicidemicelle-clay composites were prepared by adding $2 \mathrm{~g} / \mathrm{L}$ montmorillonite to the micelle solution (2.8 mM ODTMA) in the presence or absence of the herbicide ( $2.1 \mathrm{mM}$ sulfentrazone) in the solution and stirred for another $24 \mathrm{~h}$.

Zeta Potential Measurements of Micelle and Herbicide-Micelle Solutions and Clay and Composite Suspensions. The samples were allowed to settle for approximately $1 \mathrm{~h}$, and a few milliliters of the suspension (of the clay, micelle-clay, and herbicide-micelle-clay composites) or the solution (of micelle and herbicide-micelle solutions) from the top of the flask was measured. $\xi$ was measured using a Zetasizer Nanosystem (Malvern Instruments, Southborough, $\mathrm{MA}$ ), where the $\xi$ was deduced from the mobility of the particles using the Smoluchowski equation.

Micelle Size Measurements. Micelles and mixed micelles solutions were prepared by addition of ODTMA $(2.8 \mathrm{mM})$, Triton X-100 (1.5 $\mathrm{mM}$ ), or both surfactants (2.8 mM ODTMA and $1.5 \mathrm{mM}$ Triton X100) (by weight) to a stirred Erlenmeyer flask with distilled water, overnight. Size measurements were made after sample filtration $(0.2$ $\mu \mathrm{m})$ by Zetasizer Nanosystem (Malvern Instruments, Southborough,
MA). The corresponding apparent hydrodynamic radii were calculated as

$$
R_{\text {app }}=\frac{k T}{6 \pi \eta D}
$$

where $k$ is the Boltzmann constant, $T$ is the absolute temperature, $D$ is the diffusion coefficient, and $\eta$ is the solvent viscosity in poise. The micelle size is expressed as apparent diameter $2 R_{\text {app }}$.

Adsorption-Desorption of Commercial Herbicides and Herbicides Solubilized in Micelles to Soils. Sulfentrazone (300, 600, or 900 $\mathrm{mg} / \mathrm{L})$ was solubilized in ODTMA $(2.8 \mathrm{mM})$, Triton X-100 (1.5 $\mathrm{mM}$ ), or both surfactants (2.8 mM ODTMA and $1.5 \mathrm{mM}$ Triton X100) and stirred overnight. An alluvial soil was added to the herbicide-micelle solutions, reaching $67 \mathrm{~g} / \mathrm{L}$. The tubes were kept under continuous agitation, reaching equilibrium (for $24 \mathrm{~h}$ ). Supernatants were separated by centrifugation at $15000 \mathrm{~g}$ for 20 $\mathrm{min}$, and the herbicide concentrations in supernatants were measured by HPLC (see below).

Adsorption isotherms (adding $0-12 \mathrm{mg}$ sulfentrazone/g soil) on a sandy or an alluvial soil $(67 \mathrm{~g} / \mathrm{L})$ of sulfentrazone $(0-800 \mathrm{mg} / \mathrm{L})$ as is or solubilized in an ODTMA solution $(3.36 \mathrm{mM})$ were obtained. The experiment was conducted in Teflon centrifuge tubes which were kept under continuous agitation for $24 \mathrm{~h}$. Supernatants were separated by centrifugation at $15000 \mathrm{~g}$ for $20 \mathrm{~min}$, and herbicide concentrations in supernatants were measured by HPLC (see below). Herbicide desorption was measured after $24 \mathrm{~h}$ by resuspending the precipitate (reaching $67 \mathrm{~g}$ soil/L) with distilled water. Supernatants were separated after $24 \mathrm{~h}$ of agitation by centrifugation, and the concentration of the desorbed herbicide in the supernatant was measured by HPLC. Sample analyses were performed in triplicate.

Herbicides Release and Leaching through Thin Soil Layers. Herbicide-micelle formulations were prepared by adding $800 \mathrm{mg} / \mathrm{L}$ herbicide (sulfentrazone or metolachlor) to ODTMA solutions (3.36$12.9 \mathrm{mM}$ for the sulfentrazone and $3.36 \mathrm{mM}$ for the metolachlor) and stirred overnight.

The release and leaching of sulfentrazone and metolachlor from herbicide-micelle formulations and from the commercial formulations was measured by applying the formulations on a thin sandy or alluvial soil layer (200 g and approximately $2 \mathrm{~cm}$ ) deposited on a filter paper (Whatman 1442-125) in a Buchner funnel (area of $7.85 \times 10^{-3} \mathrm{~m}^{2}$ ). A second filter paper was placed on top of the soil to ensure uniform water distribution and to minimize disruption of the soil surface. No herbicide adsorption was obtained on the filter paper. Sulfentrazone leaching was also studied from the alluvial soil after washing it (10 pore volumes) to remove the dissolved organic matter. The herbicide-micelle and commercial formulations (Boral for sulfentrazone and Dual-Gold for metolachlor) were applied as solutions at a rate of $10.2 \mathrm{mg}$ ai per funnel, equivalent to $1300 \mathrm{~g} / \mathrm{ha}$. Water was applied as a control. Soil pore volume was measured. The funnels were irrigated 8-14 times with $50 \mathrm{~mm}$ of water $(40 \mathrm{~mL}$ per funnel $)$ at uniform intervals between irrigations. The leachates were collected after each irrigation, and herbicide concentrations were measured by HPLC. Each treatment was performed in triplicate.

Herbicide Analysis. Supernatants were filtered with acrodisc (polypropylene) filters (Pall Corp., MA) of $0.45 \mu \mathrm{m}$ pore diameter. The herbicides were analyzed by HPLC (Agilent Technologies 1200 series) equipped with a diode array detector set at 254 and $225 \mathrm{~nm}$ for sulfentrazone and metolachlor, respectivly. The HPLC column was a LiChroCARTR 250-4 PurospherR STAR RP-18 (5 $\mu \mathrm{m})$ (Merck), operating at flow rate of $0.8 \mathrm{~mL} \mathrm{~min}{ }^{-1}$. For sulfentrazone detection, the mobile phase was $50 \%$ acetonitrile and $50 \%$ water with trifluoroacetic acid, $\mathrm{pH} \sim 3$. For metolachlor detection, the mobile phase was $70 \%$ acetonitrile and $30 \%$ water.

\section{RESULTS AND DISCUSSION}

Sulfentrazone Solubilization in Micelles. Zeta potential $(\xi)$ of montmorillonite, ODTMA micelles, and an ODTMAclay composite and $\xi$ of ODTMA micelles as a function of sulfentrazone solubilized were monitored (Table 2). The $\xi$ 
Table 2. Zeta Potential of ODTMA Micelles $(2.8 \mathrm{mM})$ and Micelles Solubilized with Sulfentrazone $(2.1 \mathrm{mM})$, Montmorillonite ( $2 \mathrm{~g} / \mathrm{L}$ ), and Montmorillonite-ODTMA Composite with and without Sulfentrazone $(2.1 \mathrm{mM})$

\begin{tabular}{lc}
\multicolumn{1}{c}{ sample } & $\zeta$ potential $(\mathrm{mV})$ \\
ODTMA & $46 \pm 5$ \\
ODTMA + SFZ & $44 \pm 3.6$ \\
clay & $-39 \pm 0.6$ \\
ODTMA + clay & $51 \pm 1.2$ \\
ODTMA + SFZ $\rightarrow$ clay & $48 \pm 4.5$
\end{tabular}

measured for montmorillonite, ODTMA micelle, and ODTMA-clay composite are in agreement with previous studies. $^{52}$ ODTMA micelle adsorption on the clay was complete and exceeded the CEC of the clay, resulting in charge reversal of the clay $(51 \pm 1.2 \mathrm{mV}) .{ }^{52}$ Surprisingly the positive $\xi$ of ODTMA-clay composite did not decrease (less positive) upon adsorption of anionic sulfentrazone (48 \pm 4.5 $\mathrm{mV}$ ) with a 0.75 sulfentrazone/ODTMA $\mathrm{mol} / \mathrm{mol}$ ratio. Furthermore, the positive $\xi$ of ODTMA micelles did not decrease upon solubilization of anionic sulfentrazone at herbicide/surfactant $\mathrm{mol}$ at a ratio of $0.25-1.5 \mathrm{~mol} / \mathrm{mol}$.

Previously, we studied sulfentrazone solubilization in ODTMA micelles at a ratio of $0.1-0.5 \mathrm{~mol} / \mathrm{mol}$ and found that upon increasing sulfentrazone concentrations solubilization in the micelles decreased from 72 to $60 \%$, respectively. ${ }^{11}$ Sulfentrazone solubilization in ODTMA micelles was explained by two mechanisms: 1 . The cationic ODTMA micelles enhance sulfentrazone dissociation resulting in anion formation which binds electrostatically to the cationic micelles. ${ }^{28} 2$. Sulfentrazone molecules can interact with the hydrophobic micelle core (solubilized into the micelle). On the basis of the suggested mechanisms, we concluded that an increase in sulfentrazone concentration in the micelles decreases the positive charge on the micelles, resulting in lower affinity of sulfentrazone to the micelle.

However, our current results demonstrate that $\xi$ of ODTMA micelles does not decrease upon sulfentrazone solubilization. Both mechanisms suggested above may take place and do not contradict the current $\xi$ findings, when considering sulfentrazone solubilization mainly in the micelle core (Figure 1B)

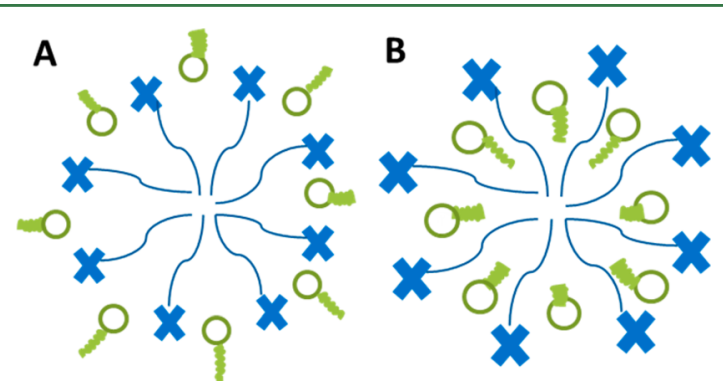

Figure 1. Suggested configurations of sulfentrazone solubilization in ODTMA micelles: (A) solubilization in the micelle shell and (B) solubilization in the micelle core.

and not at the surface (Figure 1A). Penetration into the core can explain (a) the decrease in solubilization upon increase in sulfentrazone concentration (solubilization limit and repulsion of excess positive changes in the micelles) and (b) the negligible changes in $\xi$ of ODTMA micelles upon sulfentrazone solubilization. This implies that the suggested mechanisms ${ }^{11}$ may be sequential with electorstatic attraction first and then sulfentrazone penetration into the micelles.

Adsorption-Desorption of Sulfentrazone Solubilized in Micelles to Soils. To maximize sulfentrazone adsorption to the soil via its solubilization in micelles which adsorb to the soil, two reactions, solubilization and micelle adsorption, need to be optimized. Herbicide solubilization may be increased by employing nonionic micelles with a lower CMC (than ODTMA) and which have high solubilization properties such as TX $100 .{ }^{49,50,53-55}$ Many studies report the synergistic effect of mixed micelles. ${ }^{56-61}$ Supporting these studies, the mixed micelles were found to have the largest micelle size (obtained from size measurements) which may enable higher solubilization due to larger core volume. The measured apparent micelle diameters of TX 100 micelles, ODTMA micelles, and the mixed micelles were 8.5, 7.5, and $9.5 \pm 0.2 \mathrm{~nm}$, respectively. Although sulfentrazone solubilization in TX100 micelles or in the mixed system may be higher than in ODTMA micelles, the latter's adsorption to the soil is predicted to be higher due to electrostatic attraction. To test the trade-off between solubilization and adsorption, sulfentrazone (300, 600, and $900 \mathrm{mg} / \mathrm{L}$ ) adsorption to an alluvial soil was studied upon its solubilization in TX 100, ODTMA, and in mixed micelles of the two surfactants (Figure 2).

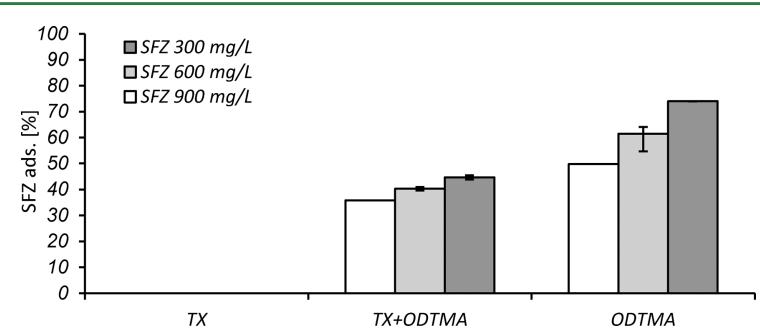

Figure 2. Adsorption of sulfentrazone (SFZ) $(300,600,900 \mathrm{mg} / \mathrm{L})$ solubilized in micelles ODTMA $(2.8 \mathrm{mM})$, TX $100(1.5 \mathrm{mM})$, and mixed micelles of both surfactants to an alluvial soil $(67 \mathrm{~g} / \mathrm{L})$.

Sulfentrazone adsorption to the soil upon its solubilization in TX 100 micelles was negligible, which demonstrates the poor adsorption of these micelles to the soil. Intermediate adsorption was obtained for the mixed micelles, and the highest adsorption was reached with the pure ODTMA micelles. These results indicate that although solubilization may be enhanced by the nonionic surfactant its adsorption to the soil is poor (lower than the adsorption of ODTMA micelles), causing lower sulfentrazone adsorption. Therefore, further adsorption and leaching studies of sulfentrazone were conducted with ODTMA micelles.

The adsorption of sulfentrazone (technical grade and Boral) and sulfentrazone $(50-800 \mathrm{mg} / \mathrm{L})$ solubilized in micelles $(3.36$ $\mathrm{mM}$ ) to the sandy soil and to the heavy alluvial soil was studied (Figure 3). The adsorption of sulfentrazone, technical grade and Boral, to both soils, sandy or alluvial, was negligible. At the $\mathrm{pH}$ values of the soils 7.5 and 7.6, respectively, the herbicide is deprotonated, i.e., in its anionic form explaining the low adsorption to the soils and supporting reports on its high leaching.

The adsorption isotherms of sulfentrazone via its solubilization in ODTMA micelles have an L-shape and were in good agreement $\left(R^{2}>0.986\right.$ or $\left.>0.972\right)$ with the Freundlich and Langmuir models, respectively (Table 3 ). 


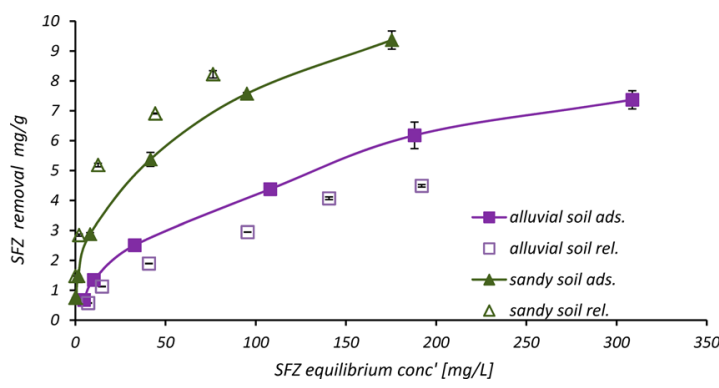

Figure 3. Adsorption/removal and desorption of Sulfentrazone (SFZ) $(50-800 \mathrm{mg} / \mathrm{L})$ solubilized in ODTMA micelles $(3.36 \mathrm{mM})$ on/from soils $(67 \mathrm{~g} / \mathrm{L})$.

Table 3. Adsorption Coefficients of Sulfentrazone Solubilized in ODTMA Micelles $(3.36 \mathrm{mM})$ to Soils $(67 \mathrm{~g}$ / L)

\begin{tabular}{lccccccc} 
& \multicolumn{3}{c}{ Langmuir } & & \multicolumn{3}{c}{ Freundlich } \\
\cline { 2 - 4 } \cline { 6 - 8 } \cline { 6 - 8 } soil & $X_{\mathrm{m}}[\mathrm{mg} / \mathrm{g}]$ & $K_{\mathrm{L}}[\mathrm{L} / \mathrm{mg}]$ & $R^{2}$ & & $K_{\mathrm{f}}[\mathrm{L} / \mathrm{mg}]$ & $n$ & $R^{2}$ \\
sandy & 9.8 & 0.057 & 0.972 & & 1.11 & 0.42 & 0.994 \\
alluvial & 8.13 & 0.014 & 0.972 & & 0.34 & 0.53 & 0.986 \\
\hline
\end{tabular}

Higher adsorption of sulfentrazone (solubilized in ODTMA-micelles) to the alluvial soil was expected since the percent of clay in this soil is approximately 35 times higher than in the sandy soil and sulfentrazone adsorption to the soil is via the electrostatic adsorption of ODTMA micelles to the clay fraction. Surprisingly sulfentrazone affinity and loading to/on the sandy soil were higher than to the alluvial soil as indicated by the affinity coefficients which are 3-4 times higher for the sandy soil (for both models) and by $X_{\mathrm{m}}$ (Langmuir loading coefficient) which is higher for the sandy soil. Furthermore, the desorption from the sandy soil presents a normal hysteresis. However, the desorption from the alluvial soil exposes suspicious excessive desorption (inverse hysteresis).

The high adsorption of sulfentrazone on the sandier soil and the high desorption from the heavier soil can be explained by analyzing the molar ratio between the surfactant and the soil CEC. Mishael et al. ${ }^{26}$ investigated sulfosulfuron adsorption to montmorillonite via its solubilization in ODTMA micelles. They found that the optimum ODTMA/CEC ( $\mathrm{mol} / \mathrm{mol})$ ratio was $\sim 1.5$. Above this ratio not all the micelles adsorbed, resulting in herbicide solubilized in unadsorbed micelles, and below this ratio (i.e., high clay concentration) ODTMA adsorbed as monomers (which have a higher affinity to the clay than the micelles) causing decomposition of micelles and release of solubilized herbicide to the solution. The adsorption of sulfentrazone on the monomer-clay complexes is much lower than on the micelle-clay complexes as reported for sulfentrazone $^{28}$ and sulfometuron. ${ }^{25}$

The ODTMA/CEC mole ratio for the adsorption experiment with the sandy and with the alluvial soil were 1 and 0.12 , respectively, which explains the higher adsorption to the sandy soil (ratio close to optimum ratio) and perhaps can explain precipitation of sulfentrazone in the experiment with the heavier soil due to the high clay concentration releasing sulfentrazone above its water solubility from the micelles. During the desorption experiment the unadsorbed sulfentrazone is released to the solution, resulting in excessive release. This implies that not all of the sulfentrazone (in the case of the alluvial soil) adsorbed but rather precipitated; therefore, the $Y$ axis denoted sulfentrazone removal and not adsorption.
These results emphasize the importance of selecting an optimal surfactant/CEC ratio.

Sulfentrazone and Metolachlor Release and Leaching from Micelle Treated and Nontreated Soils. Sulfentrazone Release and Leaching from Micelle Treated and Nontreated Soils. We suggest that the cationic micelles solubilized with sulfentrazone adsorb to the soil which in turn inhibits both herbicide release from the micelles and leaching through the soil without compromising weed control. $^{11}$ To test the reduction in sulfentrazone leaching when applied to that solubilized in micelles, Boral, sulfentrazone $(800 \mathrm{mg} / \mathrm{L})$ solubilized in ODTMA micelles (3.36-13 $\mathrm{mM}$ ), and water (control) were applied to a thin layer of the sandy or alluvial soil, and the soils were irrigated with $0-8$ pore volumes; also, sulfentrazone concentrations in the leachates were measured (Figures 4). Sulfentrazone
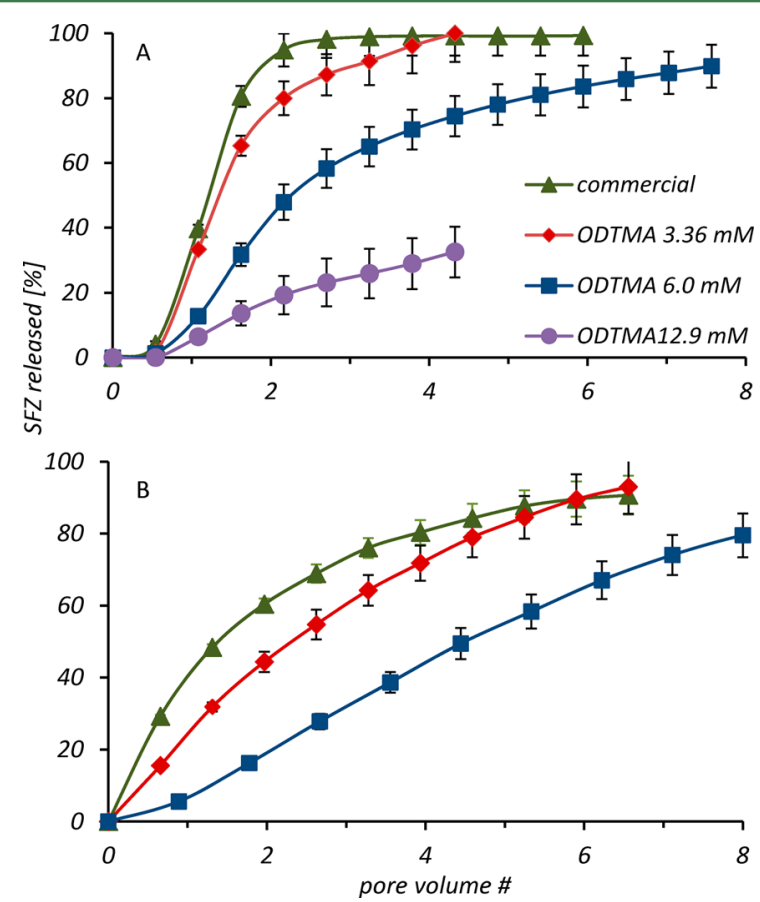

Figure 4. Sulfentrazone (SFZ) release and leaching applied as a commercial Boral or sulfentrazone-micelle formulations applied on thin layer of soil (A) alluvial or (B) sandy.

leaching from the commercial formulation was higher than from the herbicide-micelle ones, through both soils. For the alluvial soil, after 2.7 pore volumes irrigations (equivalent to $300 \mathrm{~mm}$ of rain), $98 \%$ of the sulfentrazone from the commercial formulation (Boral) leached through the soil layer, whereas 87,58 , and $23 \%$ leached from the $3.36,6.0$, and $12.9 \mathrm{mM}$ ODTMA formulations, respectively. In the sandy soil, after 2.6 pore volume irrigations (equivalent to $200 \mathrm{~mm}$ of rain), $69 \%$ of the SFZ from the commercial formulation leached through the soil layer, whereas 54 and $27 \%$ leached from the 3.36 and $6.0 \mathrm{mM}$ ODTMA formulations, respectively.

The decrease in sulfentrazone leaching upon the increase in surfactant concentration emphasizes the contribution of the adsorbed micelles to the inhibited leaching.

Effect of Soil on Sulfentrazone Release and Leaching from Micelle Treated and Nontreated Soils. In agreement with the adsorption/desorption results (Figure 3), sulfentrazone leaching (applied solubilized in micelles) through the alluvial soil 
was higher than through the sandy soil (Figure 4b). An irrigation of 2.6 pore volumes resulted in $87 \%$ and $48 \%$ leaching of sulfentrazone applied to the alluvial and sandy soils, respectively. The enhanced leaching from the alluvial soil can be explained by micelle decomposition caused by "excess" clay in the alluvial soil as described and calculated in the adsorption experiments. For the leaching experiments it is problematic to estimate the volume of soil the micelles can access, since the micelle solution is applied on top of the soil and not in a batch array. Therefore, the micelle/CEC $\mathrm{mol} / \mathrm{mol}$ ratio was not calculated, but the enhanced leaching from the alluvial soil implies that the optimal ratio was exceeded.

The enhanced leaching of sulfentrazone from the commercial formulation through the alluvial soil, obviously, cannot be explained by a low micelle/CEC $\mathrm{mol} / \mathrm{mol}$ ratio (Figure $4 \mathrm{a}$ ). Four alternative explanations were raised and examined.

1. High adsorption of sulfentrazone to iron oxides, common in this sandy soil (Hamra), which could explain inhibited leaching. It is well documented that herbicides have high affinity to oxides. ${ }^{62-64}$ However, sulfentrazone (technical and as Boral) adsorption experiments to iron oxides resulted in negligible adsorption, excluding this mechanism.

2. Transport of herbicides via their interaction with the dissolved organic matter (DOM) may also be considered. Indeed, the percent of DOM in the alluvial soil was higher than in the sandy soil. To test this hypothesis the DOM was washed from the alluvial soil and the leaching experiment was repeated with the washed soil; however, no significant differences were observed (Figure 5) indicating that in this case the DOM had a minor role in sulfentrazone transport (not surprising since both are negatively charged).

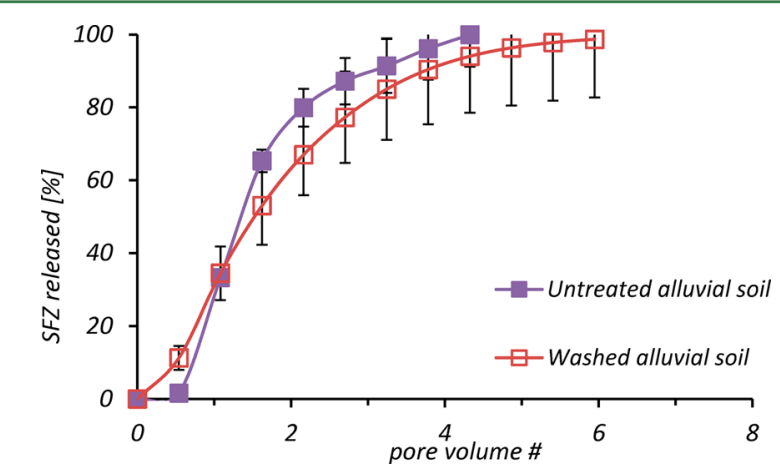

Figure 5. Sulfentrazone release and leaching from a sulfentrazonemicelle (3.36 mM ODTMA) formulation applied on a thin soil layer of an untreated alluvial soil and on a thin soil layer of alluvial soil in which the DOM was washed.

3. The well aggregated structure of the alluvial soil (in comparison to the sandy soil) may decrease the accessible soil adsorption sites, enhancing sulfentrazone leaching. If so, the leaching pattern, higher leaching through the alluvial soil, of other herbicides should be the same. As seen in Figure 6, metolachlor leaching through the two soils is not very different, and when plotted as a function of number of washes the leaching through both soils is nearly the same. In contrast, upon plotting the leaching of sulfentrazone as a function of number of washes the leaching from the alluvial soil remained

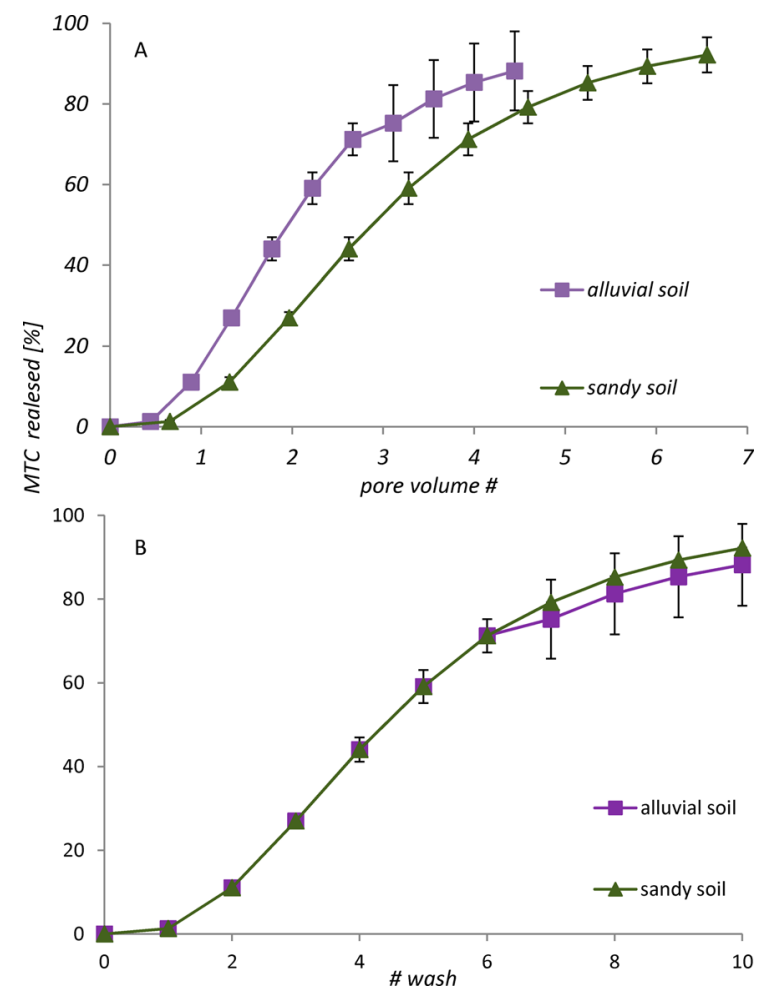

Figure 6. Metolachlor (S-dual gold) release and leaching from a thin layer of alluvial soil as a function of (A) irrigation pore volume and (B) number of irrigations.

higher (plot not shown). This suggests that the soil structure and that the kinetics are not the governing factors.

4. Finally, the repulsion of anionic sulfentrazone from the alluvial soil with a high clay concentration may explain the enhanced leaching through this soil. Metolachlor which is nonionic would not be as repelled from the heavy soil, and indeed its leaching through the sandy and heavy soils is not very different (Figure 6).

Metolachlor Release and Leaching from Micelle Treated and Nontreated Soils. Leaching of metolachlor (solubilized in $3.36 \mathrm{mM}$ ODTMA or as the commercial formulation, S-Dual Gold) through the alluvial soil was tested, in order to demonstrate that employing herbicides in micelles reduces their leaching is valid not just for sulfentrazone (Figure 7).

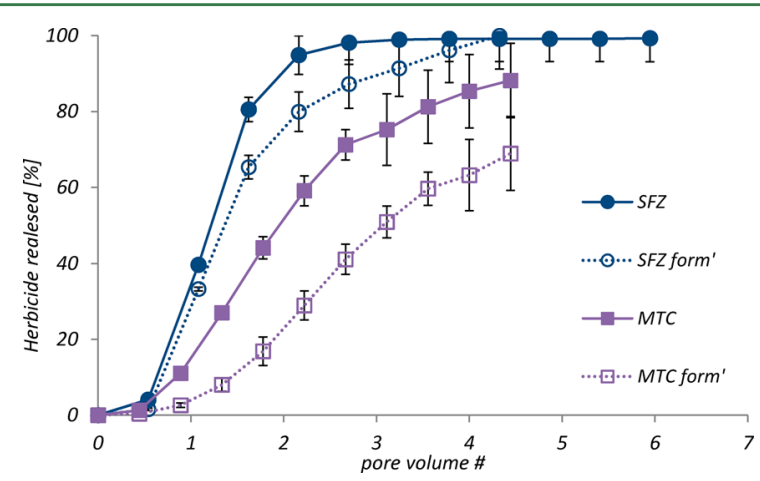

Figure 7. Herbicide release from commercial and herbicide-micelle (ODTMA $3.36 \mathrm{mM}$ ) formulations applied on thin layer of alluvial soil. 
Metolachlor leaching in both cases applied as the commercial or as a micelle formulation was restricted in comparison to sulfentrazone leaching. After irrigating 2.7 pore volumes, 98 and $87 \%$ of the sulfrentrazone leached from the commercial and from the micelle formulation, respectively, whereas metolachlor leaching after irrigating 2.7 pore volumes reached only 71 and $41 \%$ of the applied herbicide as the commercial or micelle formulation, respectively. As expected, leaching of anionic sulfentrazone was higher than the leaching of nonionic metolachlor.

Metolachlor leaching was inhibited when employed solubilized in micelles. Furthermore, metolacher leaching was inhibited to a higher degree $(\sim 50 \%)$ than that of sulfentrazone $(\sim 16 \%)$.

As discussed above due to a low surfactant/CEC $\mathrm{mol} / \mathrm{mol}$ ratio in the alluvial soil micelle decomposition and monomer adsorption are expected. Nevertheless, metolachlor (unlike sulfentrazone) has high affinity to organo-clay complexes ${ }^{34}$ which explains its high inhibition even under conditions of micelle decomposition.

Metolachlor leaching, when applied solubilized in micelles (3.36 mM ODTMA), was reduced by up to 2 -fold, and sulfentrazone leaching, when applied solubilized in micelles (13 mM ODTMA), was reduced by up to 5-fold. These reduction rates are much higher than values previously reported for in situ slow release formulations. ${ }^{39,65}$

Gamiz et al. reported a reduction in fluometuron leaching of 1.25 upon adding $12.5 \%$ (surfactant $(w) /$ soil $(w)){ }^{39}$ Rodriguez-Cruz et al. studied the retention of three pesticides in soil columns modified with ODTMA (w/w ratio of $2.5 \%)$. The leaching of linuron, atrazine, and metalaxyl through the soil treated with ODTMA was 3-4-fold less than from the nontreated soil. ${ }^{65}$ In the current study, for sulfentrazone, not only were ODTMA doses much lower but herbicide reduction rates were higher. Sulfentrazone leaching was reduced by 5 -fold upon adding only $0.3 \%$ ODTMA, and metolachlor leaching was reduced by 2 -fold upon adding only $0.075 \%$ ODTMA.

The current study demonstrated four advantages when comparing the leaching retention to other reports on in situ soil modification: (1) Upon adding low loadings of ODTMA $(0.075-0.3 \% \mathrm{w} / \mathrm{w})$, herbicide leaching is significantly reduced. (2) ODTMA has been reported as toxic to microbial soil processes. ${ }^{66}$ However, surfactant concentrations employed in this study are below the reported limit $(1-10 \% \mathrm{w} / \mathrm{w})$. (3) The herbicide is solubilized in the micelles as a formulation and both are applied to the soil at the same time, in comparison to the two step application in other reports (soil modification and then herbicide application). (4) An optimized surfactant/soil $\mathrm{CEC} \mathrm{mol} / \mathrm{mol}$ ratio is taken into account to maximize herbicide retention via micelle adsorption.

To conclude, herbicides were solubilized in micelles, and these formulations were applied to soils, for reduced herbicide leaching. This mode of application is more efficient than the common two step application, soil modification, and then herbicide application. Sulfentrazone (as Boral or technical) adsorption to a sandy or alluvial soil was negligible; however, its adsorption via its solubilization in ODTMA micelles was significant and in good agreement with the Freundlich and Langmuir models. An optimized surfactant/soil CEC mol/mol ratio was taken into account to maximize herbicide retention via micelle adsorption. Even upon adding low loadings of surfactant $(0.075-0.3 \% \mathrm{w} / \mathrm{w}$ soil $)$ herbicide leaching was significantly reduced.

\section{AUTHOR INFORMATION}

\section{Corresponding Author}

*(Y.G.M.) Tel.: 972-8-948-9171. Fax: 972-8-948-9856. E-mail: mishael@agri.huji.ac.il.

\section{Present Address}

${ }^{\dagger}$ Samaria and the Jordan Rift regional R Center, Science park, Ariel, Israel.

\section{Funding}

This research was supported by internal funding for applied sciences of Hebrew University.

Notes

The authors declare no competing financial interest.

\section{ABBREVIATIONS USED}

SFZ, sulfentrazone; MTC, metolachlor; ODTMA, octadecyltrimethyl ammonium; TX, Triton X-100; ai, active ingredient; ads, adsorbed; rel, released

\section{REFERENCES}

(1) Carter, A. D. Herbicide movement in soils: principles, pathways and processes. Weed Res. 2000, 40, 113-122.

(2) Rice, P. J.; Anderson, T. A.; Coats, J. R. Degradation and persistence of metolachlor in soil: Effects of concentration, soil moisture, soil depth, and sterilization. Environ. Toxicol. Chem. 2002, 21, 2640-2648.

(3) Gevao, B.; Semple, K. T.; Jones, K. C. Bound pesticide residues in soils: a review. Environ. Pollut. 2000, 108, 3-14.

(4) Clerk, H. Sulfentrzone; Establishment of Tolerances; United States Environmental Protection Agency: 1997; pp 10703-10708.

(5) Miller, J. I. Pesticide Fact Sheet, Registration of a New Chemical; United States Environmental Protection Agency: 1997.

(6) Hela, D. G.; Lambropoulou, D. A.; Konstantinou, A. K.; Albanis, T. A. Environmental monitoring and ecological risk assessment for pesticide contamination and effects in Lake Pamvotis, northwestern Greece. Environ. Toxicol. Chem. 2005, 24, 1548-1556.

(7) Ahrens, H. W. Herbicide Handbook, 8th ed.; Weed Science Society of America: Champaign, IL, 2002.

(8) Ahrens, H. W. Herbicide Handbook, 7th ed.; Weed Science Society of America: Champaign, IL, 1994.

(9) Patakioutas, G.; Albanis, T. A. Adsorption-desorption studies of alachlor, metolachlor, EPTC, chlorothalonil and pirimiphos-methyl in contrasting soils. Pest Manage. Sci. 2002, 58, 352-362.

(10) Bakhtiary, S.; Shirvani, M.; Shariatmadari, H. Adsorptiondesorption behavior of 2,4-D on NCP-modified bentonite and zeolite: Implications for slow-release herbicide formulations. Chemosphere 2013, 90, 699-705.

(11) Ziv, D.; Mishael, Y. G. Herbicide solubilization in micelle-clay composites as a basis for controlled release sulfentrazone and metolachlor formulations. J. Agric. Food Chem. 2008, 56, 9159-9165.

(12) Bojemueller, E.; Nennemann, A.; Lagaly, G. Enhanced pesticide adsorption by thermally modified bentonites. Appl. Clay Sci. 2001, 18, 277-284.

(13) Bruna, F.; Pavlovic, I.; Celis, R.; Barriga, C.; Cornejo, J.; Ulibarri, M. A. Organohydrotalcites as novel supports for the slow release of the herbicide terbuthylazine. Appl. Clay Sci. 2008, 42, 194-200.

(14) Cardoso, L. P.; Celis, R.; Cornejo, J.; Valim, J. B. Layered double hydroxides as supports for the slow release of acid herbicides. J. Agric. Food Chem. 2006, 54, 5968-5975.

(15) Carrizosa, M. J.; Calderon, M. J.; Hermosin, M. C.; Cornejo, J. Organosmectites as sorbent and carrier of the herbicide bentazone. Sci. Total Environ. 2000, 247, 285-293.

(16) Celis, R.; Hermosin, M. C.; Carrizosa, M. J.; Cornejo, J. Inorganic and organic clays as carriers for controlled release of the herbicide hexazinone. J. Agric. Food Chem. 2002, 50, 2324-2330.

(17) Cornejo, L.; Celis, R.; Dominguez, C.; Hermosin, M. C.; Cornejo, J. Use of modified montmorillonites to reduce herbicide 
leaching in sports turf surfaces: Laboratory and field experiments. Appl. Clay Sci. 2008, 42, 284-291.

(18) El-Nahhal, Y.; Nir, S.; Polubesova, T.; Margulies, L.; Rubin, B. Lezaching, phytotoxicity, and weed control of new formulations of alachlor. J. Agric. Food Chem. 1998, 46, 3305-3313.

(19) El-Nahhal, Y.; Nir, S.; Serban, C.; Rabinovitz, O.; Rubin, B. Organo-clay formulation of acetochlor for reduced movement in soil. $J$. Agric. Food Chem. 2001, 49, 5364-5371.

(20) Huh, K. M.; Min, H. S.; Lee, S. C.; Lee, H. J.; Kim, S.; Park, K. A new hydrotropic block copolymer micelle system for aqueous solubilization of paclitaxel. J. Controlled Release 2008, 126, 122-129.

(21) Kenawy, E. R.; Sakran, M. A. Controlled release formulations of agrochemicals from calcium alginate. Ind. Eng. Chem. Res. 1996, 35, $3726-3729$.

(22) Kumar, J.; Nisar, K.; Shakil, N. A.; Walia, S.; Parsad, R. Controlled release formulations of metribuzin: Release kinetics in water and soil. J. Environ. Sci. Health, Part B 2010, 45, 330-335.

(23) Li, J. F.; Li, Y. M.; Dong, H. P. Controlled release of herbicide acetochlor from clay/carboxylmethylcellulose gel formulations. J. Agric. Food Chem. 2008, 56, 1336-1342.

(24) Li, J. F.; Jiang, M.; Wu, H.; Li, Y. M. Addition of Modified Bentonites in Polymer Gel Formulation of 2,4-D for Its Controlled Release in Water and Soil. J. Agric. Food Chem. 2009, 57, 2868-2874.

(25) Mishael, Y. G.; Undabeytia, T.; Rytwo, G.; PapahadjopoulosSternberg, B.; Rubin, B.; Nir, S. Sulfometuron incorporation in cationic micelles adsorbed on montmorillonite. J. Agric. Food Chem. 2002, 50, 2856-2863.

(26) Mishael, Y. G.; Undabeytia, T.; Rabinovitz, O.; Rubin, B.; Nir, S. Sulfosulfuron incorporated in micelles adsorbed on montmorillonite for slow release formulations. J. Agric. Food Chem. 2003, 51, 22532259.

(27) Nennemann, A.; Mishael, Y.; Nir, S.; Rubin, B.; Polubesova, T.; Bergaya, F.; van Damme, H.; Lagaly, G. Clay-based formulations of metolachlor with reduced leaching. Appl. Clay Sci. 2001, 18, 265-275.

(28) Polubesova, T.; Nir, S.; Rabinovitz, O.; Borisover, M.; Rubin, B. Sulfentrazone adsorbed on micelle-montmorillonite complexes for slow release in soil. J. Agric. Food Chem. 2003, 51, 3410-3414.

(29) Radian, A.; Mishael, Y. G. Characterizing and designing polycation - Clay nanocomposites as a basis for imazapyr controlled release formulations. Environ. Sci. Technol. 2008, 42, 1511-1516.

(30) Sanchez-Verdejo, T.; Undabeytia, T.; Nir, S.; Maqueda, C.; Morillo, E. Environmentally friendly slow release formulations of alachlor based on clay-phosphatidylcholine. Environ. Sci. Technol. 2008, 42, 5779-5784.

(31) Undabeytia, T.; Nir, S.; Rubin, B. Organo-clay formulations of the hydrophobic herbicide norflurazon yield reduced leaching. J. Agric. Food Chem. 2000, 48, 4767-4773.

(32) Undabeytia, T.; Mishael, Y. G.; Nir, S.; Papahadjopoulossternberg, B.; Rubin, B.; Morillo, E.; Maqueda, C. A novel system for reducing leaching from formulations of anionic herbicides: Clayliposomes. Environ. Sci. Technol. 2003, 37, 4475-4480.

(33) Undabeytia, T.; Recio, E.; Maqueda, C.; Sanchez-Verdejo, T.; Balek, V. Slow diuron release formulations based on clayphosphatidylcholine complexes. Appl. Clay Sci. 2012, 55, 53-61.

(34) El-Nahhal, Y.; Nir, S.; Serban, C.; Rabinovitch, O.; Rubin, B. Montmorillonite-phenyltrimethyl ammonium yields environmentally improved formulations of hydrophobic herbicides. J. Agric. Food Chem. 2000, 48, 4791-4801.

(35) Mishael, Y. G.; Undabeytia, T.; Rabinovitz, O.; Rubin, B.; Nir, S. Slow-release formulations of sulfometuron incorporated in micelles adsorbed on montmorillonite. J. Agric. Food Chem. 2002, 50, 28642869.

(36) Undabeytia, T.; Nir, S.; Gomara, M. J. Clay-vesicle interactions: Fluorescence measurements and structural implications for slow release formulations of herbicides. Langmuir 2004, 20, 6605-6610.

(37) Singh, M.; Tan, S.; Sharma, S. D. Leaching and sorption of norflurazon in soils as affected by cationic surfactants. Bull. Environ. Contam. Toxicol. 2002, 68, 901-907.
(38) Rodriguez-Cruz, M. S.; Sanchez-Martin, M. J.; Andrades, M. S.; Sanchez-Camazano, M. Modification of clay barriers with a cationic surfactant to improve the retention of pesticides in soils. J. Hazard. Mater. 2007, 139, 363-372.

(39) Gamiz, B.; Celis, R.; Hermosin, M. C.; Cornejo, J. Soil Clay Modification with Spermine and Its Effect on the Behavior of the Herbicide Fluometuron. Soil Sci. Soc. Am. J. 2012, 76, 432-440.

(40) Boyd, S. A.; Mortland, M. M.; Chiou, C. T. Sorption characteristics of organic-compounds on hexadecyltrimethylammonium-smectite. Soil Sci. Soc. Am. J. 1988, 52, 652-657.

(41) Smith, L. W.; Bayer, D. E. Soil adsorption of diuron as influenced by surfactants. Soil Sci. 1967, 103, 328-\&.

(42) Gaynor, J. D.; Volk, V. V. Surfactant effects on picloram adsorption by soils. Weed Sci. 1976, 24, 549-552.

(43) Elworthy, P. H.; Lipscomb, F. J. Solubilization of Griseofulvin by Nonionic Surfactants. J. Pharm. Pharmacol. 1968, 20, 817-824.

(44) Dunaway, C. S.; Christian, S. D.; Scamehorn, J. F. Overview and history of the study of solubilization. Surf. Sci. Ser. 1995, 55, 3-31.

(45) Rosen, M. J. Surfactants and interfacial phenomena, 3rd ed.; John Wiley \& Sons, Inc.: Hoboken, NJ, 2004; p 444.

(46) Scamehorn, J. F.; Harwell, J. H. Surfactants in Emerging Technologies. In Surfactant Science Series, Rosen, M. J., Ed.; Marcel Dekker: New York, 1987; Vol. 26, p 169.

(47) Zana, R. Aqueous surfactant-alcohol systems: a review. Adv. Colloid Interface Sci. 1995, 57, 1-64.

(48) Nagarajan, R.; Ruckenstein, E. Theory of Surfactant SelfAssembly - a Predictive Molecular Thermodynamic Approach. Langmuir 1991, 7, 2934-2969.

(49) Sanchez-Camazano, M.; Rodriguez-Cruz, S.; Sanchez-Martin, M. J. Evaluation of component characteristics of soil-surfactantherbicide system that affect enhanced desorption of linuron and atrazine preadsorbed by soils. Environ. Sci. Technol. 2003, 37, 27582766.

(50) Wang, P.; Keller, A. A. Partitioning of hydrophobic organic compounds within soil-water-surfactant systems. Water Res. 2008, 42, 2093-2101.

(51) El-Nahhal, Y.; Nir, S.; Polubesova, T.; Margulies, L.; Rubin, B. Movement of metolachlor in soil: effect of new organo-clay formulations. Pestic. Sci. 1999, 55, 857-864.

(52) Zadaka, D.; Radian, A.; Mishael, Y. G. Applying zeta potential measurements to characterize the adsorption on montmorillonite of organic cations as monomers, micelles, or polymers. J. Colloid Interface Sci. 2010, 352, 171-177.

(53) West, C. C. Surfactant-enhanced solubilization of tetrachloroethylene and degradation products in pump and treat remediation. ACS Symp. Ser. 1992, 491, 149-158.

(54) Rodriguez-Cruz, M. S.; Sanchez-Martin, M. J.; SanchezCamazano, M. Enhanced desorption of herbicides sorbed on soils by addition of triton X-100. J. Environ. Qual. 2004, 33, 920-929.

(55) Xiarchos, I.; Doulia, D. Effect of nonionic surfactants on the solubilization of alachlor. J. Hazard. Mater. 2006, 136, 882-888.

(56) Khan, A.; Marques, E. F. Synergism and polymorphism in mixed surfactant systems. Curr. Opin. Colloid Interface Sci. 1999, 4, 402-410.

(57) Bergstrom, M.; Eriksson, J. C. A theoretical analysis of synergistic effects in mixed surfactant systems. Langmuir 2000, 16, $7173-7181$.

(58) Zhu, L. Z.; Feng, S. L. Synergistic solubilization of polycyclic aromatic hydrocarbons by mixed anionic-nomonic surfactants. Chemosphere 2003, 53, 459-467.

(59) Mishael, Y. G.; Dubin, P. L. Toluene solubilization induces different modes of mixed micelle growth. Langmuir 2005, 21, 98039808.

(60) Zhou, W. J.; Zhu, L. Z. Solubilization of polycyclic aromatic hydrocarbons by anionic-nonionic mixed surfactant. Colloids Surf., A 2005, 255, 145-152.

(61) Yang, K.; Zhu, L. Z.; Xing, B. S. Enhanced soil washing of phenanthrene by mixed solutions of TX100 and SDBS. Environ. Sci. Technol. 2006, 40, 4274-4280. 
(62) Kirkwood, R. C. Use and mode of action of adjuvants for herbicides - a review of some current work. Pestic. Sci. 1993, 38, 93102.

(63) Leone, P.; Negre, M.; Gennari, M.; Boero, V.; Celis, R.; Cornejo, J. Adsorption of imidazolinone herbicides on smectite-humic acid and smectite-ferrihydrite associations. J. Agric. Food Chem. 2002, 50, 291-298.

(64) Rocha, W. S. D.; Regitano, J. B.; Alleoni, L. R. F.; Tornisielo, V. L. Sorption of imazaquin in soils with positive balance of charges. Chemosphere 2002, 49, 263-270.

(65) Rodriguez-Cruz, M. S.; Sanchez-Martin, M. J.; Andrades, M. S.; Sanchez-Camazano, M. Retention of pesticides in soil columns modified in situ and ex situ with a cationic surfactant. Sci. Total Environ. 2007, 378, 104-108.

(66) Sarkar, B.; Xi, Y. F.; Megharaj, M.; Krishnamurti, G. S. R.; Bowman, M.; Rose, H.; Naidu, R. Bioreactive Organoclay: A New Technology for Environmental Remediation. Crit. Rev. Environ. Sci. Technol. 2012, 42, 435-488. 